\title{
ERRATUM
}

Roberto Martínez-Alvarez • Antonio Herrera •

Pedro Ramiro

\section{Analytical challenge}

\section{Solution to spectroscopy challenge 9}

Published online: 17 September 2005

(C) Springer-Verlag 2005

We apologize to the reader that there is a printer's error in the PDF and printed version of this Solution to spectroscopy challenge 9 .

The correct structure 2 is given below:<smiles>CSc1nc(Cc2ccc([N+](=O)[O-])cc2)oc1C</smiles>

The online version of the original article can be found at http://dx.doi.org/10.1007/s00216-005-3268-3.

R. Martínez-Alvarez $(\bowtie) \cdot$ A. Herrera $\cdot$ P. Ramiro

Universidad Complutense de Madrid,

28040 Madrid, Spain

e-mail: rma@quim.ucm.es 